Citation: N. Elstrodt-Wefing, U. Ritterfeld (2020) Home-schooling during the pandemic: A push for digital education in German classrooms?! Media Education 11(2): 27-36. doi: 10.36253/me-9686

Received: July, 2020

Accepted: September, 2020

Published: December, 2020

Copyright: () 2020 N. Elstrodt-Wefing, U. Ritterfeld. This is an open access, peer-reviewed article published by Firenze University Press (http://www. fupress.com/me) and distributed under the terms of the Creative Commons Attribution License, which permits unrestricted use, distribution, and reproduction in any medium, provided the original author and source are credited.

Data Availability Statement: All relevant data are within the paper and its Supporting Information files.

Competing Interests: The Author(s) declare(s) no conflict of interest.

\section{Home-schooling during the pandemic: A push for digital education in German classrooms?!}

\author{
Home-schooling durante la pandemia: un impulso per \\ l'educazione digitale nelle classi tedesche?!
}

\author{
Nadine Elstrodt-Wefing, Ute Ritterfeld \\ Technische Universität Dortmund \\ E-mail: nadine.elstrodt-wefing@tu-dortmund.de; ute.ritterfeld@tu-dortmund.de
}

\begin{abstract}
The COVID-19 home-schooling situation has become a catalyst for educational institutions to search for and deploy innovative solutions within a relatively short period of time. Since many teachers have been forced to employ technical or digital approaches with which they have had little to no prior experience, this situation might give rise to a push for digital education. In the present study we employed a two-part interview-survey to investigate how home-schooling affects German teachers' general technical affinity and their digital teaching competence during home-schooling. Furthermore, the qualitative properties of the implementation of home-schooling were explored. The results of the study revealed that the teachers' digital teaching competence, but not their technical affinity, changed during the pandemic. An increase in digital teaching competence was only identifiable for the first weeks of the pandemic. Qualitative analyses showed that the teachers used three different types of educational tools: (1) digital tools, (2) analogue tools, and (3) technical tools. Over the course of the pandemic the usage of those tools became more structured. However, structures were mostly built on a micro-level, e.g., by individual teachers for their classes; no macro-structures like class-comprehensive rules or even strategy papers for digital teaching were developed.
\end{abstract}

Keywords: digital teaching competence, teaching tools, teaching strategies, homeschooling.

Riassunto. La situazione di home-schooling dovuta al COVID-19 è diventata un catalizzatore per le istituzioni educative impegnate a cercare e implementare soluzioni innovative in breve tempo. Poiché molti insegnanti sono stati costretti ad adottare approcci tecnici o digitali di cui avevano poca o nessuna esperienza, questa situazione potrebbe diventare una spinta propulsiva per l'istruzione digitale. Nel presente studio è stata condotta un'indagine attraverso un'intervista, composta da due parti, volta ad indagare come l'home-schooling influenzi l'affinità tecnica generale degli insegnanti tedeschi e la loro competenza digitale nelle pratiche di insegnamento a distanza. Inoltre, è stata condotta un'analisi qualitativa rispetto l'attuazione dell'home-schooling. I risultati dello studio hanno rivelato che la competenza didattica digitale degli insegnanti, ma non la loro affinità tecnica, è cambiata durante la pandemia. Si è registrato un aumento della competenza nell'insegnamento digitale solo per le prime settimane 
della pandemia. Le analisi qualitative hanno mostrato che gli insegnanti hanno utilizzato tre diversi tipi di strumenti didattici: (1) strumenti digitali, (2) strumenti analogici e (3) strumenti tecnici. Nel corso della pandemia l'uso di tali strumenti è diventato più strutturato. Tuttavia, le strutture sono state per lo più costruite su un micro-livello, ad esempio da singoli insegnanti per le loro classi; non sono state sviluppate macro-strutture come regole di classe o documenti sulle strategie per l'insegnamento digitale.

Parole chiave: competenza didattica digitale, strumenti didattici, strategie didattiche, home-schooling.

\section{INTRODUCTION}

With centuries-old, lecture-based approaches to teaching and entrenched institutional biases, the slow pace of change in Germany's academic institutions especially with regard to the application of new technologies - is lamentable. However, risk-control measures implemented during the COVID-19 pandemic resulted in total closures of schools with millions of students and their teachers being confronted with temporary 'homeschooling'. As home-schooling involves the usage of technology, the COVID-19 situation has become a catalyst for educational institutions to search for and deploy innovative solutions within a relatively short period of time. Since many teachers have been forced to employ technical or digital solutions with which they have had little to no prior experience, this situation can also be viewed as a huge field experiment for the study of behavioural change. In the present study we attempt to capture parts of the changes prompted by these circumstances.

We employed a two-part interview-survey to investigate how home-schooling affects teachers' general technical affinity and their digital teaching competence over a period of twelve weeks. Furthermore, the qualitative properties of the implementation of home-schooling are explored.

\section{DIGITALIZATION DEFICIT IN GERMAN SCHOOLS}

In 2000, scientific studies by the nationwide initiative Schools on the Net [Schulen am Netz], showed that Germany was trailing behind other European countries in terms of technical equipment in schools and internet practice (Weinreich \& Schulz-Zander, 2000). Even today, more than two decades later, little to no progress or adjustments to international standards can be observed (Scheiter \& Lachner, 2019) Despite the early demand by schools for technical change, the strategy Education in the digital world was not launched by the Standing Conference of the Ministers of Education and Cultural Affairs (Kultusministerkonferenz - KMK) until 2016 (KMK \& Bogedan,
2016). The strategy formulates clear goals for digital education in schools and higher education institutions and defines the orientation of educational content. Since the necessary equipment and training for digital education has, however, not yet been fulfilled at many German schools, these goals are a long way off. According to the International Computer and Information Literacy Study (Eickelmann, Gerick, Drossel, \& Bos, 2013) Germany even ranks lowest in the use of computers in the classroom in comparison to 21 European educational-systems. Moreover, key results of a representative study carried out across Germany in 2015 show that German pupils and teachers are dissatisfied with the existing IT equipment in schools. They have complained about the absence of hardware and the lack of high-performance internet access (in approximately $70 \%$ of the schools the internet is only accessible in special computer rooms) and have been demanding better equipment for digital learning (Scheiter \& Lachner, 2019).

However, the ICILS also shows that there is no indication of a general aversion to technology. The majority of teachers hold a positive attitude towards digital media and they also state that they use it in their private lives. One in six teachers even describe themselves as a technology fan and in recent years there has been an increase in positive attitudes towards the use of digital media in classrooms among teachers. While $23 \%$ of teachers rejected the use of digital media in 2012, three years later this number had decreased to $5 \%$ (Kempf, 2015).

Despite the teachers' positive attitudes, the potential of digital media is not exploited in the classrooms and the majority of teachers mostly (85\%) use conventional worksheets and books. Kempf (2015) reports that digital media, mostly desktop computers, are only used in rare cases and that there is little to no variance in didactic purpose. For example, computers are used for the presentation of learning outcomes but rarely tailored towards educational goals (Tappe, 2017).

It is still being discussed within the political and scientific realms how this digitalization deficit in the German educational system might be overcome (Scheiter\& Lachner, 2019). Research mostly focuses on the usage of specific technical devices or programs and rarely 
deals with questions regarding effective implementation. Much research has been carried out addressing students in upper grades and only a few studies have focused on primary- or elementary school pupils. Moreover, children with special needs are almost completely ignored (Starke, Leinweber, \& Ritterfeld, in press). This neglect is a major disadvantage because these groups in particular could benefit from the structural advantages of a digital learning environment such as: additivity, decentralization and deregulation of learning locations, interactivity and the possibility for individualized and specific feedback (Herzig \& Grafe, 2007).

\section{TEACHER-RELATED FACTORS AFFECTING THE IMPLEMENTATION OF DIGITAL MEDIA}

Research indicates that besides the digitalization deficit in German schools there are several teacherrelated factors that affect the implementation of digital media. The factors of age and gender are high on this list, as demonstrated by several studies: Women do not use digital media (most studies focus on the use of computers) as frequently as men and therefore show less technology-related self-efficacy (Ray, Sormunen, \& Harris, 1999; Schumacher \& Morahan-Martin, 2001). Women also tend to show greater negative attitudes and fears towards technology (Beil et al. 2015). Age-related research found negative associations between age and computer-related self-efficacy (Reed et al. 2005) and between age and computer use (Marquie et al. 2002).

The strongest predictors for a more widespread use of digital media in education are, however, the perceived advantages of technology as well as the educators' attitudes (Bullock, 2004; Lawless \& Pellegrino, 2007; Lee et al. 2005). Both are in turn affected by a variety of factors such as the complexity of the technology or the ability to observe the technology in use (Knezek \& Christensen, 2002; Nicolle \& Lou, 2008)

Moreover, educators tend to use digital media more often if they are proficient in its application and if they feel that they are utilising it highly effectively. Largescale studies focusing on characteristics of successful teacher training (Desimone, 2011) show that both aspects (teachers' perceived proficiency as well as their self-efficacy) can be influenced positively if the opportunity for active participation is offered and if the transfer of newly acquired knowledge into teachers' own lessons is facilitated (e.g. by supporting them with a coaching or mentoring program). Of course, systematically planned teacher training cannot be equated with the homeschooling situation during the coronavirus pandemic.
Yet since it has similar characteristics (active application of technology in own lessons), it is conceivable that it causes similar effects. Assuming that many teachers are not only gaining more experience with but are also becoming more sophisticated in their use of technical and digital devices during this process, the following questions are to be pursued in this study:

- Do the teachers' digital teaching competence and general technical affinity change over the course of home-schooling during the COVID-19 pandemic?

- Which factors determined the teachers' digital teaching competence and its possible increase?

We further aim to explore the quality of home-schooling and its development guided by the following research questions:

- Which tools and teaching strategies are used for home-schooling during the COVID-19 pandemic?

- How does the use of teaching tools and teaching strategies change during the course of home-schooling?

\section{METHOD}

\subsection{Sample}

Sample size was $N=109$ teachers at T1 resp. T0 (mean age $M=41.16$ years, $S D=12.13 ; 76 \%$ female; work experience, $M=156$ month, $S D=123.7)$. The majority of the teachers $(n=102)$ live and work in the state of North Rhine-Westphalia. The information given in Table 1 presents details about the school type, size and the teachers' main subject areas of expertise. The majority of the teachers are employed at medium-sized schools. Interestingly, approximately half of the teachers in the sample are currently working at schools for children with special needs and two thirds are teachers of mathematics. Most of the teachers ( $n=102$ out of the initial sample of $n=109$ ) took part in the follow up (T2) (mean age, $M=40.99$ years, $S D=12.28 ; 77.77 \%$ female; work experience, $M=154$ month, $S D=126.8$ ).

\subsection{Procedure}

The study took place during the Covid-19 pandemic in Germany and involved two surveys. The first survey (T1) took place a few weeks into the complete lockdown during Spring 2020, included all schools and focused on the teaching tools and strategies initially applied. The second survey (T2) took place approximately eight weeks after the total lockdown and before the summer break. It focused on possible changes in the usage of teaching 
Table 1. School type, -size and the teachers subject area (T1).

\begin{tabular}{llllll}
\hline Subject area & Freq. & School-size & Freq. & Type of school & Freq. \\
\hline German & 70 & Small $:<150$ students & 16 & Special education & 57 \\
Mathematics & 33 & Medium: $150-500$ students & 70 & Elementary school & High-school \\
Science & 19 & Big: $500-1000$ students & 9 & \\
Physical education & 13 & Large: $>1000$ students & 14 & & \\
Theology & 21 & & & \\
Technology & 7 & & & \\
Economics & 6 & & & \\
Social/political Studies & 6 & & & \\
English & 6 & & & \\
Biology & 5 & & & \\
Music & 5 & & & \\
Other & 23 & & & \\
\hline
\end{tabular}

technology during the course of the pandemic. A twopart interview-survey with open and multiple-choice questions was administered via telephone. The participants were recruited via snowball sampling through personal contacts of the research group and were asked to participate in both an initial survey and a follow-up a few weeks later.

\subsection{Instruments}

Participating teachers were first asked some questions about their current working situation: the size and type of their school, their teaching subjects, and in which state of Germany they are employed. We also requested their age, sex and length of work experience (in years).

"Technical affinity \& digital teaching competence". Technical affinity was assessed at both points of measurement using the TAEG questionnaire (Fragebogen zur Technikaffinität - Einstellung zu und Umgang mit elektronischen Geräten [Questionnaire on affinity for technology - attitude to and handling of electronic devices]), Karrer, Glaser, Clemens, \& Bruder, 2009). The TAEG contains four subscales: (1) technical competence (four items; e.g., To me it's easy to learn how to use a new technical device.), (2) enthusiasm (five items; e.g., I love owning new technical devices.), (3) positive attitude (five items; e.g., Technical devices increase security.), and (4) negative attitude (five Items; e.g., Technical devices cause stress.). Each scale consisted of Likert-type items ranging from $1=$ not at all to $5=$ very much. Within the sample data, reliability analyses yielded sufficiently good Cronbach's alphas at both measurement points ranging between .68 and .83 (T1: technical competence: $\alpha=$ .81 , enthusiasm: $\alpha=.83$, negative attitude: $\alpha=.66$, posi- tive attitude: $\alpha=68$; T2: technical competence: $\alpha=.78$, enthusiasm: $\alpha=.86$, negative attitude: $\alpha=.69$, positive attitude: $\alpha=68$ ). Subscales were labeled using information about TAEG sub scale as well as the measurement points such as TAEG-enth.-T1, TAEG-enth.-T2, etc.

Teachers were asked to rank their competence in the usage of digital technology for teaching using a percentage scale (0-100\%). At the first point of measurement subjects were asked for their estimate on their current digital teaching competence (DTC-1) and how they would rank this competence prior to the pandemic (DTC-0); this past time period was then considered as T0. In order to establish changes evolving during the course of the pandemic teachers' evaluations of their digital teaching competence were also requested at the second point of measurement (DTC-2).

"Application of teaching strategies". In order to find out which teaching strategies were applied at the beginning or after a few weeks of home-schooling, a standardized interview was performed. Four initial open questions requested general information about the teaching situation (e.g., How much time did you have to prepare yourself and your students for home-schooling?). In the second and main part of the interview, teachers were asked which digital, analogue and technical tools they applied during the pandemic to teach their students. They were further asked with describing their teaching strategy for each tool as well as its advantages and disadvantages. At T2 participants were asked whether they were still using these tools and which other tools they had added to their toolbox in the meantime.

"Changes in usage". To further understand why changes in toolboxes and teaching strategies might have taken place, we finished by posing additional open questions concerning teacher education programs during the 
pandemic, and collaborations with colleagues and the head teacher. It was additionally requested which aspects were perceived as obstructive resp. beneficial for homeschooling. The teachers' answers to the open questions were collected, removed of redundancy and irrelevance, and categorized.

\section{RESULTS}

\subsection{Statistical Results}

"Descriptive Results". The average rating for the DTC lies above 50 percent for all three measurement points. At T1 $(M=69.69 ; S D=16.66)$ the DTC is rated approximately nine percentage points higher than at T0 $(M=59.85 ; S D=18.74)$. There is no continuing increase of the DTC at T2. In contrast to the increase from DTCT0 to DTC-T1 a slight decrease from DTC-T1 to DTCT2 $(M=67.29)(S D=17.24)$ can be observed.

Table 2 summarizes the results of the descriptive statistics for the DTC at the three measurement points per type of school. At T0 the high school teachers rated their DTC approximately six to eight percentage points higher than the elementary- and special education schoolteachers. With nine percentage points, the increase in DTC from T0 to T1 is very similar across the three groups. Likewise, the three groups show a decrease from DTC-T1 to DTC-T2. The ratings of the special needs teachers declined the most.
Table 3 shows the average scores and the standard deviation for the four subscales of the TAEG for measurement points one and two. The changes between the two points of measurement are marginal for every subscale.

"The Wilcoxon Signed-Rank Test" was carried out to investigate whether the DTC and the teachers' ratings for the subscales of the TAEG changed during the course of home-schooling. As the results in Table 4 show, the Wilcoxon Signed-Rank Test indicated that ratings for the DTCT0 differ from the ratings of DTC-T1 and DTC-T2. There was no difference in DTC ratings between $\mathrm{T} 1$ and $\mathrm{T} 2$ as well as for the teachers' rating of all four scales of the TAEG.

"Regression analyses". Stepwise regressions were carried out to investigate which factors affect the teachers' ratings of their DTC. Three multiple regression models with DTC-T0, DTC-T1 and DTC-T2 as dependent variables and the four subscales of the TAEG, age, and gender as independent variables were thus calculated.

With the models 1,2 , and 3 , it was investigated which factors predict the DTC-T0, DTC-T1 and DTC-T2. The teachers' DTC before the pandemic (T0, Model 1) was best explained with the TAEG-comp. ( $b$ $=.38$ ). With this model $13 \%$ of the variance could be explained. The factor TAEG-comp. was also included as the only explaining factor in model 2 . Here it explained $18 \%$ of the variance $(b=.38)$. For DTC-T2 two factors were included in model 3: TAEG-comp. $(b=.52)$ and age $(b=.20)$. With model $3.33 \%$ of the variance could be explained.

Table 2. Descriptive statistics for the DTC at T0, T1 and T2 per type of school.

\begin{tabular}{|c|c|c|c|c|c|c|c|c|}
\hline & \multicolumn{2}{|c|}{ T0 } & \multicolumn{2}{|c|}{$\mathrm{T} 1$} & \multirow{2}{*}{$\frac{\mathrm{T} 0-\mathrm{T} 1^{*}}{M}$} & \multicolumn{2}{|c|}{$\mathrm{T} 2$} & \multirow{2}{*}{$\frac{\mathrm{T} 1-\mathrm{T} 2^{\star *}}{M}$} \\
\hline & $M$ & $S D$ & $M$ & $S D$ & & $M$ & $S D$ & \\
\hline Special education & 59.51 & 17.328 & 68.62 & 14.92 & 9.11 & 65.95 & 18.53 & -02.67 \\
\hline Elementary school & 57.14 & 20.28 & 66.32 & 19.42 & 9.18 & 66.00 & 16.45 & -00.32 \\
\hline Secondary school & 65.00 & 20.39 & 74.48 & 17.48 & 9.48 & 72.68 & 14.17 & $-1,8$ \\
\hline
\end{tabular}

Annotation. ${ }^{*} \mathrm{~T} 0-\mathrm{T} 1=$ difference in DTC between the two measurement points; ${ }^{*} \mathrm{~T} 0$ - T1 $=$ difference in DTC between the two measurement points.

Table 3. Descriptive statistics of the four scales of the TAEG.

Subscales TEAG

\begin{tabular}{cccccccccc} 
& \multicolumn{2}{c}{ technical competence } & \multicolumn{2}{c}{ enthusiasm } & \multicolumn{2}{c}{ negative attitude } & \multicolumn{2}{c}{ positive attitude } \\
\cline { 2 - 8 } & $M$ & $S D$ & $M$ & $S D$ & $M$ & $S D$ & $M$ & 3.67 \\
\hline T1 & 3.29 & .86 & 2.70 & .91 & 2.59 & .60 & .55 \\
T2 & 3.33 & .83 & 2.70 & .90 & 2.66 & .53 & 3.75 & .51 \\
\hline
\end{tabular}


Table 4. Results of the Wilcoxon Signed-Rank Test.

\begin{tabular}{lcc}
\hline Paired Variables & $Z$ & $p$ \\
\hline DTC-T0/DTC-T1 & -6.977 & .000 \\
DTC-T0/DTC-T2 & -.798 & .000 \\
DTC-T1/DTC-T2 & -.561 & .575 \\
TAEG-tech.comp.-T1-T2 & -.456 & .642 \\
TAEG-enthu.-T1-T2 & -.956 & .339 \\
TAEG-pos.att.-T1-T2 & -1.929 & .054 \\
TAEG-neg.atti.-T1-T2 & -1.169 & .242 \\
\hline
\end{tabular}

Table 5. Results of the stepwise regression analysis

\begin{tabular}{llccc}
\hline Variable & & Model 1 & Model 2 & Model 3 \\
\hline Constant & $t$ & -.010 & .006 & .003 \\
Age & $B(S E)$ & & & $-.205^{\star}$ \\
TAEG-comp. & B $(S E)$ & $.345^{\star * *}$ & $.386^{\star * *}$ &. $.521^{\star * *}$ \\
& Beta & $.356^{\star * *}$ & $.434^{\star * *}$ & $.504^{\star * *}$ \\
& $R^{2}$ & .133 & .188 & .334 \\
& $F$ & 13.371 & 20.382 & 23.353 \\
\hline
\end{tabular}

Annotation. Model 1: DTC-T0, Model 2: DTC-T1, Model 3: DTCT2. The significant results of multiple stepwise regression analyses and the model with the greatest clarification are reported. ${ }^{*} p<.05$, ${ }^{\star *} p<.01,{ }^{* * *} p<.001$.

\subsection{Results of the qualitative analysis}

"Tools and teaching strategies used for home-schooling". Analysis of interview data indicated that the teachers used three different types of tools for educating their students during the pandemic (multiple answers were possible; tools are listed by frequency of use): (1) digital tools used by 92 teachers, (2) analogue tools used by 77 teachers and (3) technical tools used by 30 teachers.

"Digital tools". As shown in Table 6 we found a great variety of digital tools. Most teachers were using more than one digital tool and stated that they used them because it was uncomplicated and saved time. Another main advantage was perceived in the digital opportunities to give feedback to the students. In addition to this, teachers thought that digital tools had a motivating effect on the students and appreciated the opportunities for differentiation. However, usage of the digital tools was frequently impaired by the students' insufficient access to the required hardware. The interviewees were also concerned about data protection.

Three major 'teaching strategies' using digital tools were identified. (1) Digital tools (e.g., e-mail programs) were mostly used to add additional explanations (e.g., learning videos): 83 cases - based on the number of tools and not on the number of teachers. (2) In approximately two-thirds of the cases $(n=75)$, digital tools like learning apps that contained exercises were established to offer practice opportunities to the students. (3) Beyond this, digital tools (e.g., WhatsApp, Zoom) were used for interactional purposes in a multitude of ways: one-to-one, group-meeting, class meeting etc. Altogether, the usage of the digital tools was rather unrestricted (no fixed schedules for Zoom meetings, no deadlines for assignments on a learning website).

"Analogue tools" (mostly worksheets or work assignments which told the students to work on a study topic in their exercise books) were used most frequently during home-schooling. The interviewees supposed that working with this kind of tool would be easier for the students than working with digital tools because they are more familiar with it. The accessibility and adaptability of the analogue tools, which were mostly sent to the students via mail or collected from the school by their parents, were also highly appreciated. However, the organizational aspects connected with the use of the analogue tools and the lack of opportunity to give direct feedback were a cause for concern.

"Teaching strategies". In comparison to the other two types of teaching tools, the use of the analogue tools was the most restricted. Mostly the students had to finish a certain amount of work in a certain amount of time. There were also fixed deadlines. Interestingly there was less consensus among the teachers regarding the question of feedback. How the necessary knowledge should be developed remained unclear in most interviews. In a few cases $(\mathrm{n}=12)$, a work schedule was added to tell the students how and/or how long they should work on a topic. Sometimes analogue tools were linked to digital tools (e.g., an assignment in an exercise book was linked to an explanatory YouTube video).

"Technical tools" (telephones in all 30 cases) were usually used to make contact with the students or their parents in order to ask about their wellbeing. The interviewees highly appreciated that the technical tools offered them the opportunity for direct and personal contact with their students. It was also mentioned that the information one can normally gain from gestures and facial expressions was lacking.

"Teaching strategies". Usually the usage of technical tools was not linked to teaching strategies but only to establish contact with the students. In some rare cases (n $=6$ ) teachers called the students to explain how to work on the assignments. 
Table 6. Overview of teaching materials used for home-schooling during the pandemic.

\begin{tabular}{lllllllll}
\hline \multicolumn{2}{c}{ Analogue tools } & \multicolumn{9}{c}{ Digital tools } & Technical tools \\
\hline Worksheets & 64 & E-mail & 37 & Learning apps & 23 & Learning video & 23 & Telephone \\
Exercise book & 16 & WhatsApp & 18 & Zoom & 10 & Moodle & 9 & 30 \\
Work schedule & 12 & Video call & 9 & Padlet & 7 & School homepage & 6 \\
Books & 12 & Antolin & 4 & Video-messenger & 3 & Microsoft-Teams & \\
Other & 7 & & & & & Other & 26 & \\
\hline
\end{tabular}

\subsection{Development of home-schooling}

$29 \%$ of the interviewed teachers declared that the methods used in home-schooling changed during the course of the pandemic. They described that usage of all (types of) teaching tools had become more structured. It became more typical to set deadlines for assignments (realized with analogue or digital tools) and work assignments were used more often. Appointments for telephone- or video-conferences also became more common (e.g., twice a week).

The majority of the interviewees (64\%) used the same teaching materials throughout the course of the pandemic. Teachers who added new materials indicated that this was motivated by the aim to offer more variety to the students. $8 \%$ of the interviewees participated in an on-the-job training during the pandemic in order to enhance their digital teaching skills. Furthermore, some teachers reported that the school management purchased new teaching materials to support and simplify digital teaching. They mostly bought user licenses (34\%) for apps or learning websites. Occasionally (8\%) the school management institutionalized the method of communication, mostly complied with data protection requirements, by offering a school-E- mail address to the teachers or expanding the school's homepage.

One quarter of the teachers reported that the school management specified requirements relating to data security (e.g., which E-mail address they must use or not use) but there were no guidelines for the use of digital resources developed at any school. Table 7 shows the five factors that were (in the perception of the teachers) the most beneficial and the most obstructive for the realization of home-schooling.

\section{DISCUSSION}

6.1 Do the teachers' digital teaching competence and general technical affinity change over the course of home-schooling during the COVID-19 pandemic?

The results of the study revealed that the teachers' 'digital teaching competence', but not their 'technical affinity', changed during the pandemic. However, a not inconsiderable increase in 'digital teaching competence' (approx. $10 \%$ ) was only identifiable for the first weeks of the pandemic. In the following weeks, the growth-curve leveled off markedly and slightly decreased until the summer break that also marked the end of home-schooling in Germany.

Our results provide first insights into the implementation of digital technology in elementary school and special education. Overall, these results are encouraging because they illustrate that the increase in 'digital teaching competence' is almost equal across the three different groups of teachers: special-education, elementary and secondary schoolteachers. Even if the teachers of the lower grades rated their 'digital teaching competence' on average 7 percentage points beneath the ratings of the secondary teachers, they still show that they make the same progress. This shows that teachers, no matter what kind of school they are working at, probably share a similar potential for development. This in turn can be

Table 7. The five most beneficial and most obstructive factors in the realization of home-schooling during the Covid-19 pandemic.

\begin{tabular}{llll}
\hline Promoting factors & Freq. & Obstructive factors & Freq. \\
\hline Colleagues: gave advice, provided material & 34 & Insufficient digital facilities of the students & 45 \\
Parents: helped students with exercises and organisation & 24 & Parents: could or would not assist their children & 16 \\
Structure/rules & 14 & Reachability of the students & 9 \\
Hardware & 13 & Time effort & 8 \\
Previous digital skills & 10 & Insufficient digital skills & 6 \\
\hline
\end{tabular}


beneficial for all groups of students but particularly so for students with special needs.

Furthermore, our results show that the teachers rate their technical competency as good and hold a positive attitude towards technical media. These findings support the position that teachers do not hold a general aversion to technology (Eickelmann et al. 2013) and that they possess sufficient basic technical skills that are required to develop the more specific skills necessary for digital teaching.

Due to the parallels of the home-schooling situation and the characteristics of successful teacher training (Desimone, 2011), we suspect that the change in the teachers' digital teaching competence was caused by the active application of technologies in their own lessons. This gives reason to believe that changes in teaching behavior can not only be caused by structured training but also by changes in external circumstances. Our study provides the opportunity to reflect on the steps that were taken to expedite the digitalization in German schools (the strategy Education in the Digital World). Since they do not address the teachers directly, and therefore miss the connection with daily teaching behavior, they may not give sufficient cause for behavioral change.

\subsection{Which factors determined the teachers' digital teaching competence and its possible increase?}

Our analyses show that the teacher's technical competence, but no other part of the construct 'technical affinity' (as defined in the TAEG; Karrer et al. 2009), is predictive of 'digital teaching competence'. However, with low rates of explanations of variance (between 3.33 $\%-18 \%$ ), it remains largely unexplained. Based on the interview findings, which show that the teachers only name one big disadvantage in relation to the use of digital teaching tools (the students' insufficient access to the required hardware), we can only assume that the perceived advantage of the tools as well as the educators' attitudes are determining not only their digital teaching competence but also its increase. In previous studies (Bullock, 2004; Lawless \& Pellegrino, 2007; Lee et al. 2005), these factors were identified as the strongest predictors for a consistent use of digital media in the classroom.

Interestingly the factor of gender was only minimally predictive of the teachers' digital teaching competence towards the end of the pandemic, and the factor of age was not predictive at any point of measurement. This is in contrast to several other studies that revealed that both factors were affecting the implementation of digital media (Ray et al. 1999; Schumacher \& Morahan-Martin, 2001). We assume that if teachers reach a certain level of expertise in digital teaching competence, then these factors become less important. Future research is needed to investigate this assumption.

6.3 Which tools and teaching strategies were used for home-schooling during the COVID-19 pandemic? How does the usage of teaching tools and teaching strategies change over the course of home-schooling?

Three different tool types were identified: (1) digital tools, (2) analogue tools and (3) technical tools. Teachers used a great variety of digital tools and experimented a lot in order to optimize their application. This result is very gratifying because it shows, once again, that the teachers have sufficient basic technical knowledge to develop digital teaching formats. In contrast to earlier research (Kempf, 2015), we also identified a certain amount of variance in the didactic purpose of the digital tools, but it cannot be assessed how well they were tailored towards educational goals.

In sum, it can be said that at the beginning of the home-schooling period digital tools were used as a kind of add-on (e.g., for additional opportunities to practise) and teachers usually used more conventional analogue teaching tools such as worksheets and books. The technical tool telephone was primarily used to make contact with the students at the beginning of the pandemic. Over the course of the pandemic the usage of technical, digital, and analogue tools became more structured. However, structures were mostly built on a micro-level, e.g., by individual teachers for their classes; no macrostructures like class-comprehensive rules or even strategy papers for digital teaching were developed. This is detrimental because a lot of information that could be valuable during a second pandemic or for further development of digital teaching will potentially be lost.

\subsection{Limitations}

Of course there are some drawbacks that have to be discussed as well. First, the informative value might be compromised by the sample size and the fact that the participants were recruited via snowball sampling through personal contacts of the research group (positive selection). We assume that this self-selection bias on the one hand favoured subjects with rather higher affinity to technology who felt less ashamed if they perceived having low technological skills. One the other hand one might argue that participation in the study was espe- 
cially attractive for those teachers who felt overwhelmed by the technological demands posed through mandatory home-schooling as we offered an opportunity to express their concerns. Possibly, both effects were neutralizing each other, but we do not know. Second, data used in this study were compiled from only one specific German state. Since structures, laws, and practices within the educational system even differ among the German states, this leads in several respects to a decrease in the validity of our findings with regard to generalizability within Germany and to other countries.

\section{CONCLUSION AND FUTURE PROSPECTS}

The results of the study revealed that the teachers' subjective digital teaching competence, but not their technical affinity, increased during the pandemic. An improvement of their digital teaching competence was only identifiable for the first weeks of the pandemic. We suspect that the change in the teachers' digital teaching competence was caused by the active application of technologies in their own lessons. Against this background, it seems imperative that future teachers training contains opportunities for active application of technologies. In the qualitative part of this study we documented which teaching tools were used during the pandemic and how they were used. This provides important information about the tools practicability that can be used during the development of teacher trainings for digital teaching.

Of course we hope that the necessities for homeschooling caused by the pandemic situation will not be replicated and we cannot simply generalize from the experiences made to a post pandemic reality. However, it is conceivable that the active application of technical media can be facilitated by other external aspects (e. g., by awarding compensation to the teachers). This assumption requires validation with further research.

\section{REFERENCES}

Beil, J., Cihlar, V., \& Kruse, A. (2015). Bereitschaft zur Akzeptanz einer internetbasierten Mobilitätsplattform bei verschiedenen Alterskohorten. Empirische Befunde des Projekts S-Mobil 100 [Willingness to accept an Internet-based mobility platform in different age cohorts. Empiric results of the project S-Mobil 100]. Zeitschrift fur Gerontologie und Geriatrie, 48(2), 142-149. https://doi.org/10.1007/s00391013-0546-0
Bullock, D. (2004). Moving from theory to practice: An examination of the factors that pre-service teachers encounter as they attempt to gain experience teaching with technology during field placement experiences. Journal of Technology and Teacher Education, 12, 211-237.

Desimone, L. M. (2011). A primer on effective professional development. Phi Delta Kappan, 92, 68-71.

Eickelmann, B., Gerick, J., Drossel, K., \& Bos, W. (Eds.). ICILS 2013 - Vertiefende Analysen zu computer- und informationsbezogenen Kompetenzen von Jugendlichen. Waxman.

Herzig, B., \& Grafe, S. (2007). Digitale Medien in der Schule: Standortbestimmung und Handlungsempfehlungen für die Zukunft; Studie zur Nutzung digitaler Medien in allgemein bildenden Schulen in Deutschland. Dt. Telekom.

Karrer, K., Glaser, C., Clemens, C., \& Bruder, C. (2009). Technikaffinität erfassen - der Fragebogen TA-EG. In C. Lichtenstein, Stößel, \& C. Clemens (Eds.), ZMMS Spektrum. Der Mensch im Mittelpunkt technischer Systeme. 8. Berliner Werkstatt Mensch-Maschine-Systeme (pp. 196-201). VDI Verlag GmbH. Retrieved from https://www.mms.tu-berlin.de/fileadmin/fg268/ Forschung/TA-EG_Fragebogen_Technikaffinitaet.pdf

Kempf, D. (2015). Digitale Schule - vernetztes Lernen. Retrieved from https://www.bitkom.org/Bitkom/Publikationen/Digitale-Schule-und-vernetztes-Lernen. html

KMK, \& Bogedan, C. (2016). Strategie der Kultusministerkonferenz. In Kultusministerkonferenz (Ed.), Strategie der Kultusministerkonferenz.

Knezek, G., \& Christensen, R. (2002). Impact of new information technologies on teachers and students. Education and Information Technologies, 7(4), 369376.

Lawless, K. A., \& Pellegrino, J. W. (2007). Professional development in integrating technology into teaching and learning: Knowns, unknowns, and ways to pursue better questions and answers. Review of Educational Research, 77(4), 575-614.

Lee, M. K. O., Cheung, C. M. K., \& Chen, Z. (2005). Acceptance of internet-based learning medium: The role of extrinsic and intrinsic motivation. Information and Management, 42(2), 1095-1104.

Marquie, J. C., Jourdan-Boddaert, L., \& Huet, N. (2002). Do older adults underestimate their actual computer knowledge? Behaviour and Information Technology, 21(4), 273-280.

Nicolle, P. S., \& Lou, Y. (2008). Technology adoption into teaching and learning by mainstream university faculty: A mixed methodology study revealing the 
how, when, why, and why not. Journal of Educational Computing Research, 39(3), 235-265.

Ray, C. M., Sormunen, C., \& Harris, T. M. (1999). Men's and women's attitudes toward computer technology: a comparison. Office Systems Research Journ, 17(1).

Reed, K., Doty, H. D., \& May, D. R. (2005). The impact of aging on self-effcacy and computer skill acquisition. Journal of Managerial Issues, 17(2), 212-228.

Scheiter, K., \& Lachner, A. (2019). DigitalPakt - was nun? Eine Positionierung aus Sicht der Lehr-Lernforschung. Unterrichtswissenschaft, 47(4), 547-564. https://doi.org/10.1007/s42010-019-00059-2

Schumacher, P., \& Morahan-Martin, J. (2001). Gender, Internet and computer attitudes and experiences. Computers in Human Behavior. (17), 95-110.

Starke, A., Leinweber, J., \& Ritterfeld, U. (in press). Designing apps to facilitate (second) language acquisition in children. In Rohlfing \& C. Müller-Brauns (Ed.), International perspectives on digital media and early literacy: The impact of digital devices on learning, language acquisition and social interaction. Routledge.

Tappe, E. H. (2017). Lernen durch Mediengestaltung Entwicklung eines Konzeptes zur Unterstützung mediendidaktischer Lehre im Schulalltag. Retrieved from https://d-nb.info/1163319627/34

Weinreich, F., \& Schulz-Zander, R. (2000). Schulen am Netz - Ergebnisse der bundesweiten Evaluation. Zeitschrift Für Erziehungswissenschaft, 3(4), 577-593. https://doi.org/10.1007/s11618-000-0054-z 